\title{
DEVELOPMENT OF HIGH VOLTAGE SOURCE FOR SPRAYING PLANTS WITH IONIZED AEROSOL
}

\author{
Sergey Antonov \\ Stavropol State Agrarian University, Russia \\ antonov_serg@mail.ru
}

\begin{abstract}
When spraying plants, a number of problems appear that contribute to the decrease in efficiency. These are such problems as the wind drift, large difference in the size between the drops, their flowing off the sheet. The application of the method of ionization of aerosol droplets eliminates these drawbacks. A jet of fluid passing through an electric field of high intensity acquires an electric charge. To obtain the effect of charging drops, it is necessary to create a corona discharge field. This field can be obtained, if two conditions are met: a) use of the electrode system "plane - string"; b) the voltage on the electrodes is not less than $15 \mathrm{kV}$. To obtain this voltage, it is necessary to develop a high-voltage voltage source that receives power from the on-board electrical network of the tractor. The initial data developing a high-voltage source of voltage are: technical parameters that determine the level and quality of the output parameters with given mass and dimensional indicators; operational, which determine the reliability of the device for the given time and working conditions; economic, which determine the cost of production and operation of the device. Some of the requirements are opposite. For example, the requirements of low mass and high reliability for a long time, minimum dimensions and cost. Therefore, when developing high voltage sources, the main criteria are highlighted and trade-off decisions are made. The development of a high-voltage source includes determination of the operating modes and selection of power transistors, calculation and selection of voltage multiplier elements, determination of the design parameters of a power transformer.
\end{abstract}

Key words: voltage, spray can, spraying, ionization, aeroion, inverter.

\section{Introduction}

Development of an intensive agricultural production technology increases its economic efficiency. However, there are new problems with foliar application, as well as plant protection from pests, diseases and weeds. Harmful factors become more and they are highly dangerous to the plants. When making preparations of foliar nutrition and plant protection, there are a number of problems that reduce the effectiveness of their use. The main problem of the study of aerosols for introduction of foliar application is the high fluid flow. This expense is due to poor quality fertilizer spraying. In addition, drops of foliar dressing flow to the surface of the earth. The development of a new generation of agricultural machines using resource-saving technologies will allow to reduce the consumption of preparations with the same efficiency, reduce their cost, increase the efficiency through the use of electrical aerosols [1-4].

The study of the spraying technological process with electrically charged aerosols is carried out in the world practice on the basis of institutes and universities under the auspices and with the financing of large firms [5;6]. In the UK, APE-80 electrostatic sprayer was designed with a rotating sprayer and external electrodes for distribution of charged particles. Marwald of Florida (USA) has developed a spray device for KWH "Kinkelder" fan sprayers. Farm Machinery Corporation (USA) has created an experimental field crop sprayer with pneumatic sprayers, which is supplied with air by a compressor. At present, SADKO (Ukraine) is presenting a commercial model of a hand-held gasoline sprayer GMD-6014 with the function of electrostatic charging of solution drops.

The most promising is a method of spraying crops by mixing ionized air with the treating plants solution (Fig. 1.). The spraying system consists of a sprayer tank (1), compressor (2), ionizer (3), high voltage source (4), pump (5), injection mixer (6), valve distributor (7), hydraulic nozzles (8), and the treated plants (9). The operation principle of the spraying system is given in $[7 ; 8]$.

The main problem of the method practical application is the use of high voltage. All existing devices for ionization of aerosol drops enable appearance of high voltage on the metal housing of the sprayer. This disadvantage leads to an increase in the requirement for its safe operation. To effectively implement the spraying technology with ionized aerosol, it is necessary to develop a high voltage source that meets the electrical safety requirements and effective spraying parameters. 


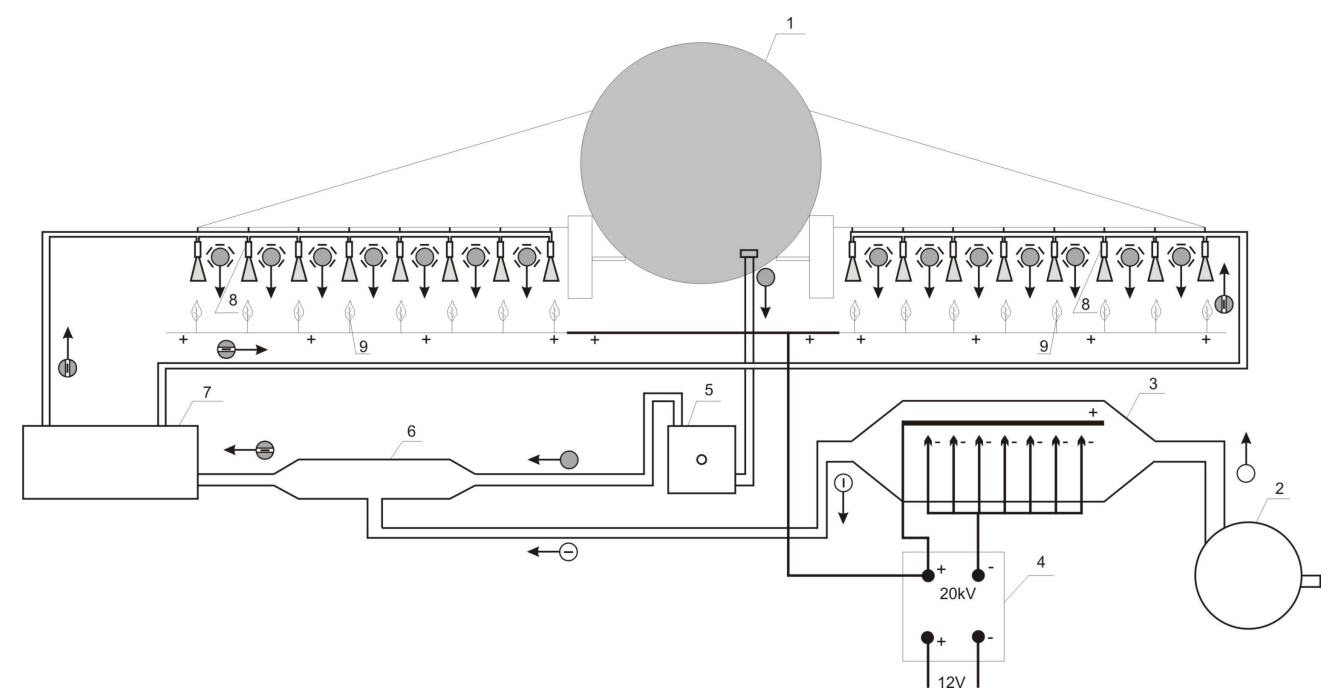

Fig. 1. Method of spraying crops: 1 - tank; 2 - compressor; 3 - ionizer; 4 - high voltage source; 5 - pump; 6 - injection mixer; 7 - valve distributor; 8 - hydraulic distributors; 9 - treated plants

\section{Materials and methods}

On-board electrical network of the tractor is a power source of an inverter high-voltage. The parameters of this network must meet the requirements for the input power level of the high-voltage source. The block diagram of the inverter high-voltage source is shown in Fig. 2 and consists of the on-board tractor network, auxiliary source, inverter, transformer, control circuit, voltage multiplier, ionizer.

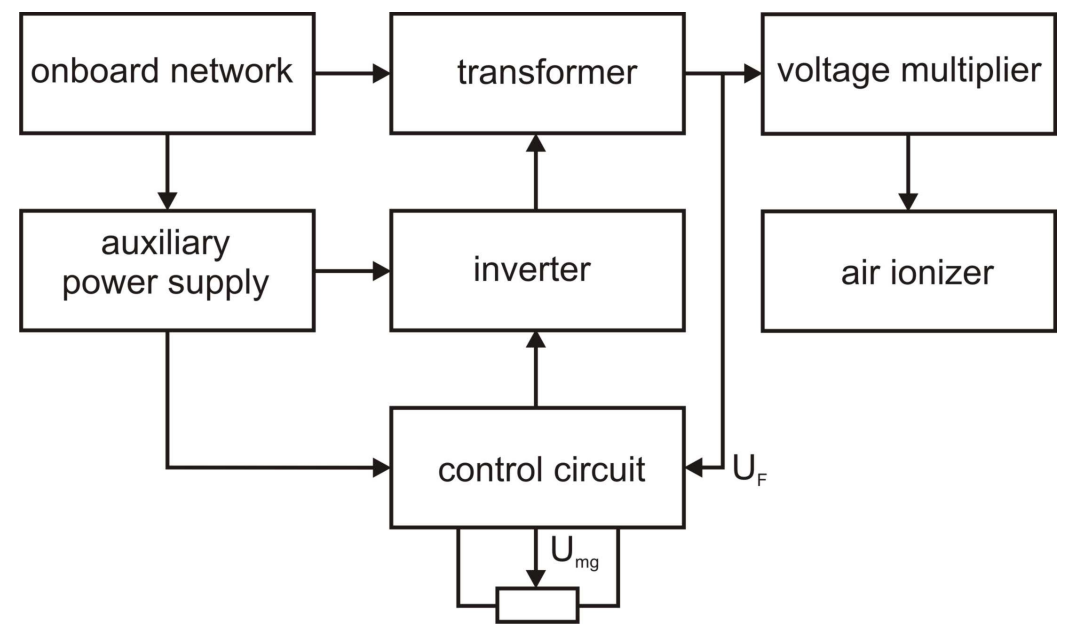

Fig. 2. Block diagram of inverter high-voltage source

The auxiliary source provides the power with stabilized voltage of the control circuit and the control circuits of the power transistors of the high-voltage source inverter. The inverter converts the $\mathrm{DC}$ voltage of the on-board network to AC, high frequency, which is fed to the transformer, where the conversion takes place according to the specified control laws. The conversion frequency value reaches $50-100 \mathrm{kHz}$, it can significantly reduce the weight and dimensions of the transformer and the converter as a whole. The switching order of the inverter power transistors is specified by the control circuit, which stabilizes the output voltage of the converter at the level specified by the reference voltage at the input of the circuit $U_{m g}$ due to the output voltage feedback (feedback voltage) $U_{F}$ by changing the pulse ratio of the power transistors. Additionally, the control circuit generates a fixed dead time pause between commutations of the power transistors to eliminate the potential for the inverter through-currents, when the transistors are turned off due to variable thermal loads. The highfrequency alternating voltage is converted by a transformer and flows to a voltage multiplier to increase it. 
The circuit diagram of the high-voltage source is shown in Fig.3.

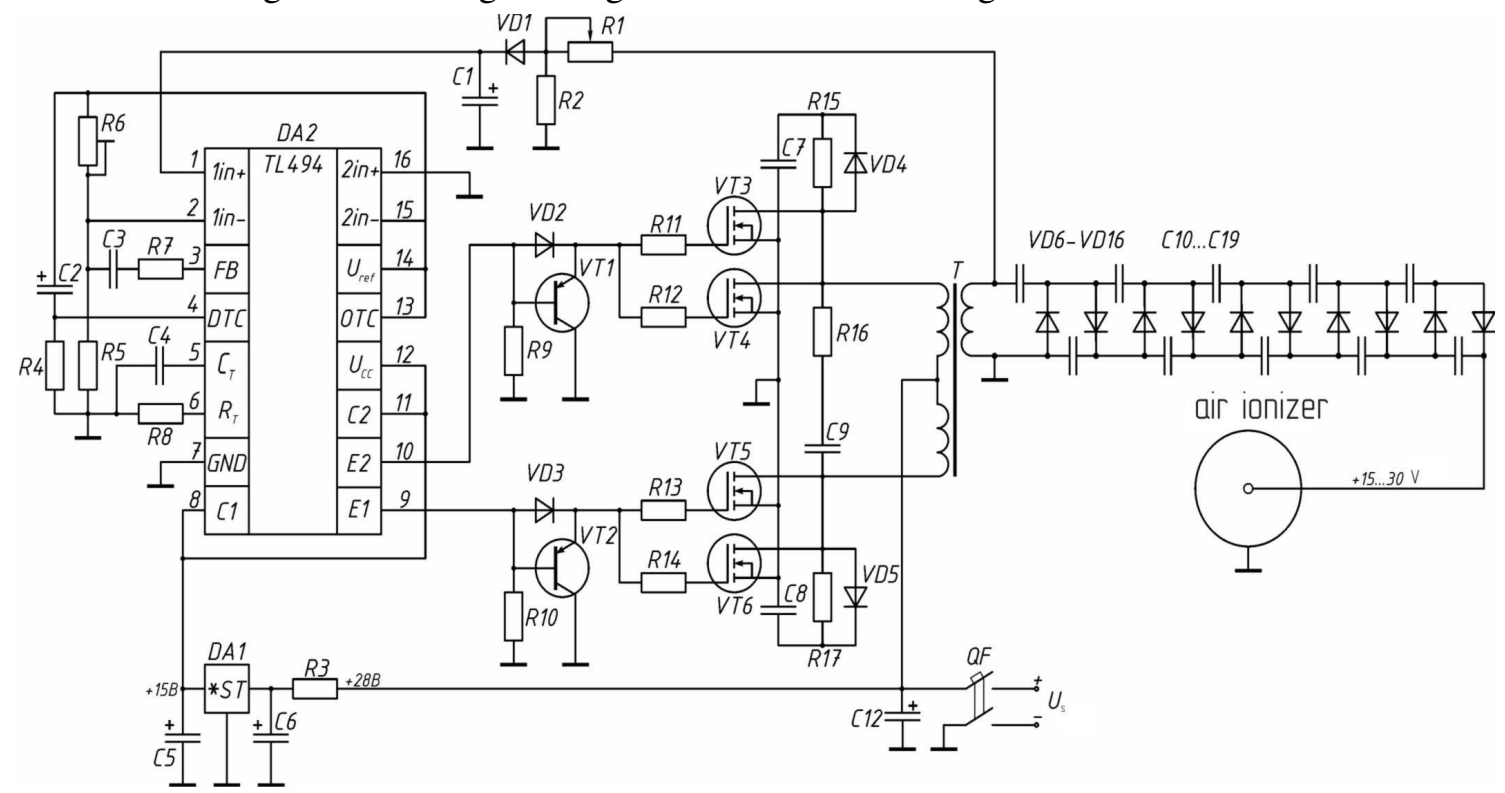

Fig. 3. Electrical schematic diagram of inverter high-voltage source

The voltage of the on-board network through the automatic switch QF, which switches on and protects the high-voltage source, goes to the filtering electrolytic capacitor $\mathrm{C} 12$, which serves to smooth sharply varying fluctuations of the voltage level of the on-board network, then the voltage goes to the transformer and the voltage source on the elements C5, C6, DA1, R3 performing the voltage regulator role of the DA2 chip power supply and the gate circuits of the power transistors VT3-VT6 at the level of $+15 \mathrm{~V}$.

The control circuit is made on the controller DA2, which generates control signals for the power switches VT3-VT6, depending on the levels of feedback signals. The VT3-VT6 switches, in turn, commute the windings of the power transformer T, thereby converting the DC voltage to the AC of the higher frequency, which is transformed by the transformer T. Next, the AC voltage of the higher frequency goes to the voltage multiplier and rises with a multiplication factor of 10 .

The frequency of conversion is set by $\mathrm{C} 4, \mathrm{R} 8$ elements and at the current power level of power transistors can quite reach the values $50 \ldots 100 \mathrm{kHz}$. Therefore, when calculating the transformer, it is necessary to take into account the exact value of the selected switching frequency of the inverter transistors. The capacitor $\mathrm{C} 2$ provides a smooth start of the converter within $0.2 \ldots 0.5 \mathrm{~s}$. Feedback on the output voltage is supplied to the non-inverting input (1) of the error amplifier No. 1 through the adjustable voltage divider R1, R2, the elements of VD1, C1 act as a low-pass filter of the feedback signal. On the inverting input (2) of the error amplifier, using the divider R5, R6, the reference voltage $(+2.5 \mathrm{~V})$ is set. When the output voltage of the converter changes, for any reason, an error is generated at the output of the error amplifier, the differential of which is negative with respect to the change in the output voltage. Therefore, if the output voltage decreases, the circuit will increase the control pulse ratio of the power transistor, thereby returning the output voltage to the normal value. If the voltage increases, the process runs in a similar way, it is only the difference that the circuit will reduce the pulse ratio of control. Elements C3, R7 adjust the amplitude-frequency response of the error amplifier.

The input transistors of the DA2 microcircuit chip are switched on according to the circuit with a common collector, while the power transistors are turned on via the pins 9, 10, DA2 and diodes VD2, VD3, and turning off with the help of the transistors VT1, VT2 that open during the moments of pause between control pulses and short the gates of the transistors VT3-VT6 on the common wire thereby, speeding up the process of turning them off.

At the moments of the control pulses action, the transistors VT1, VT2 are closed by reverse voltage on the diodes VD2, VD3, when the current flows through them. This circuit design reduces the closing time of the transistors VT3-VT6 and reduces the dynamic losses due to their switching. Elements C7, VD4, R15 and C8, VD5, R17 serve as damping circuits and serve to drain energy from 
the transistor at the time it is turned off (current interruption). Elements C9, R16 and C10, R18 serve as damping circuits for the power transformer windings.

Calculation of the high voltage source includes: determination of operating modes and selection of power transistors; calculation and selection of protection elements of power transistors against switching overvoltages; calculation and selection of voltage multiplier elements; calculation of electrical and design parameters of the power transformer.

\section{Results and discussion}

Calculation of the voltage multiplier is the main factor affecting the applied voltage to the ionizer electrodes. The voltage multiplier consists of a combination of diodes and capacitors (Fig. 4.) and is an AC voltage converter from a low-voltage source to high DC voltage.

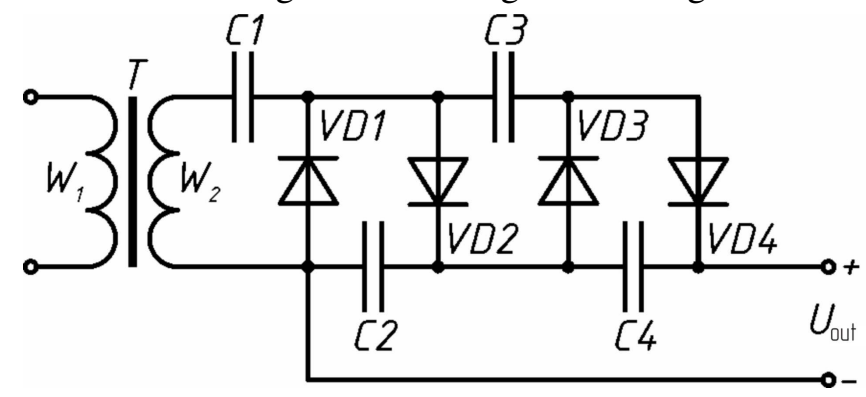

Fig. 4. Half-wave serial multiplier

The work of a half-wave serial multiplier occurs in several stages. During the negative halfwavelength voltage, the capacitor $\mathrm{C} 1$ is charged through the open diode VD1 to the amplitude value of the applied voltage $U_{a}$. When a positive half-wavelength voltage is applied to the input of the multiplier, the capacitor C2 is charged through the open diode VD2 to the voltage of $2 U_{a}$. During the next stage, the negative half-wavelength, the capacitor C3 is charged through the diode VD3 to the voltage of $2 U_{a}$. At the next positive half-wavelength, the capacitor $\mathrm{C} 4$ is charged to the voltage of $2 U_{a}$. Obviously, the multiplier starts up over several periods of alternating voltage. The constant output voltage is the sum of the voltages on the series-connected and constantly recharged capacitors $\mathrm{C} 2$ and $\mathrm{C} 4$ and is $4 U_{a}$.

Based on the conducted calculations, the experimental sample of a high-voltage source for the spray system was developed, Fig. 5.

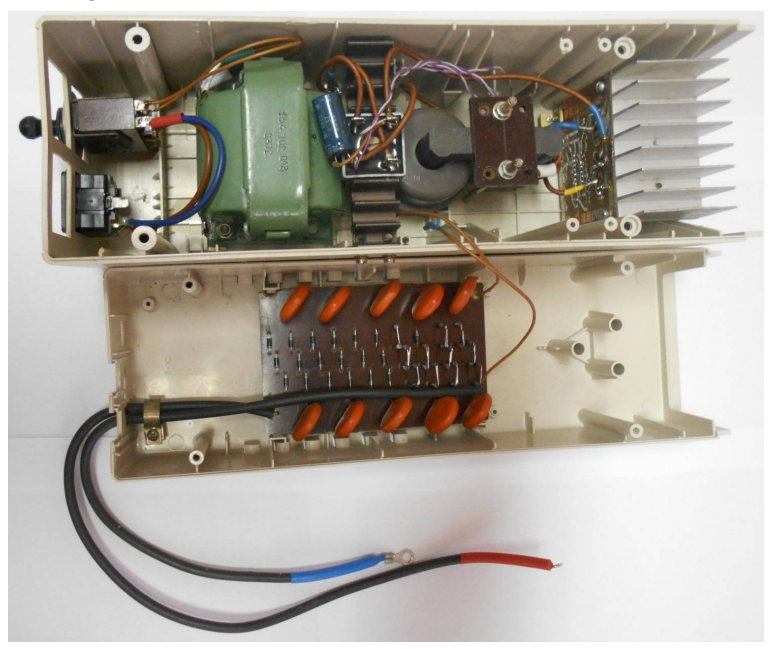

Fig. 5. Experimental sample of high-voltage source

The dependence of the multiplier output voltage $U_{\text {out }}$ with a multiplication factor $m=12$ on the change in the capacitance of capacitors as well as the dependence of the output voltage on the power supply frequency is shown in Fig. 6. The external characteristic of the multiplier is shown in Fig. 7. 
a)

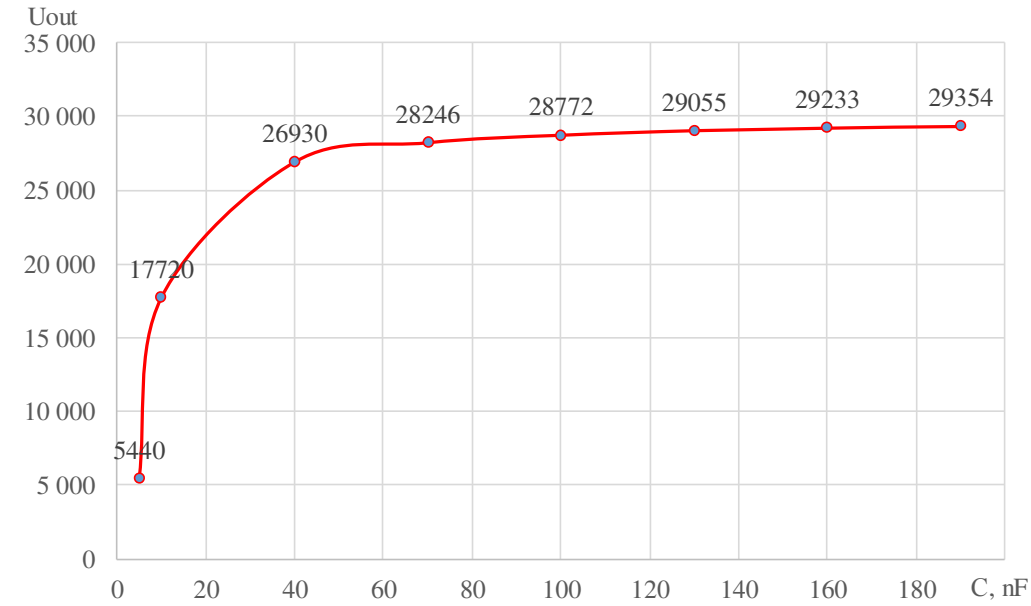

b) Uout

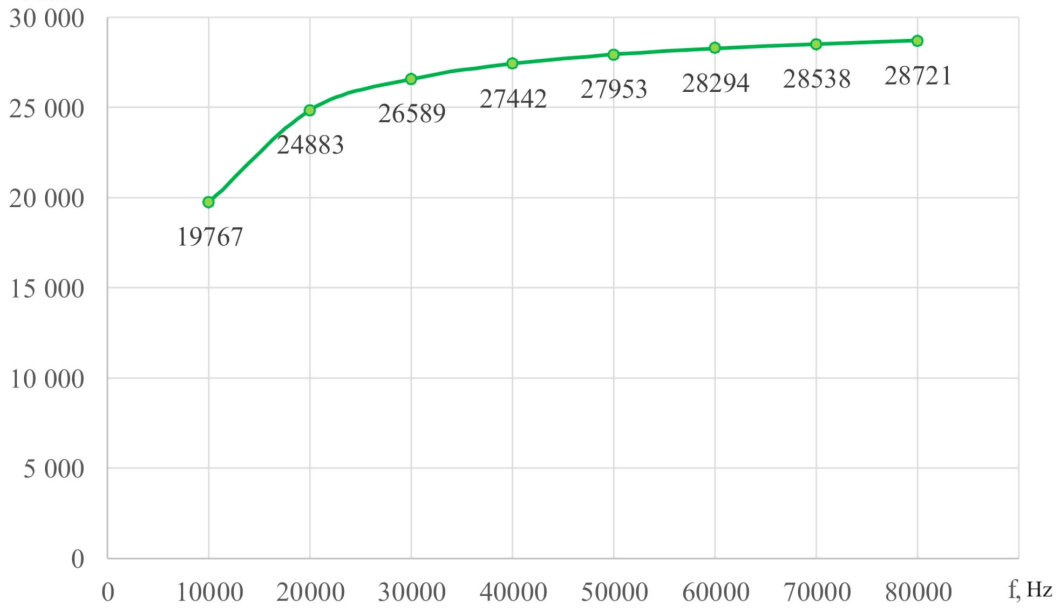

Fig. 6. Dependency graph: $\mathrm{a}-U_{\text {out }}=f(c) ; \mathrm{b}-U_{\text {out }}=f(f)$

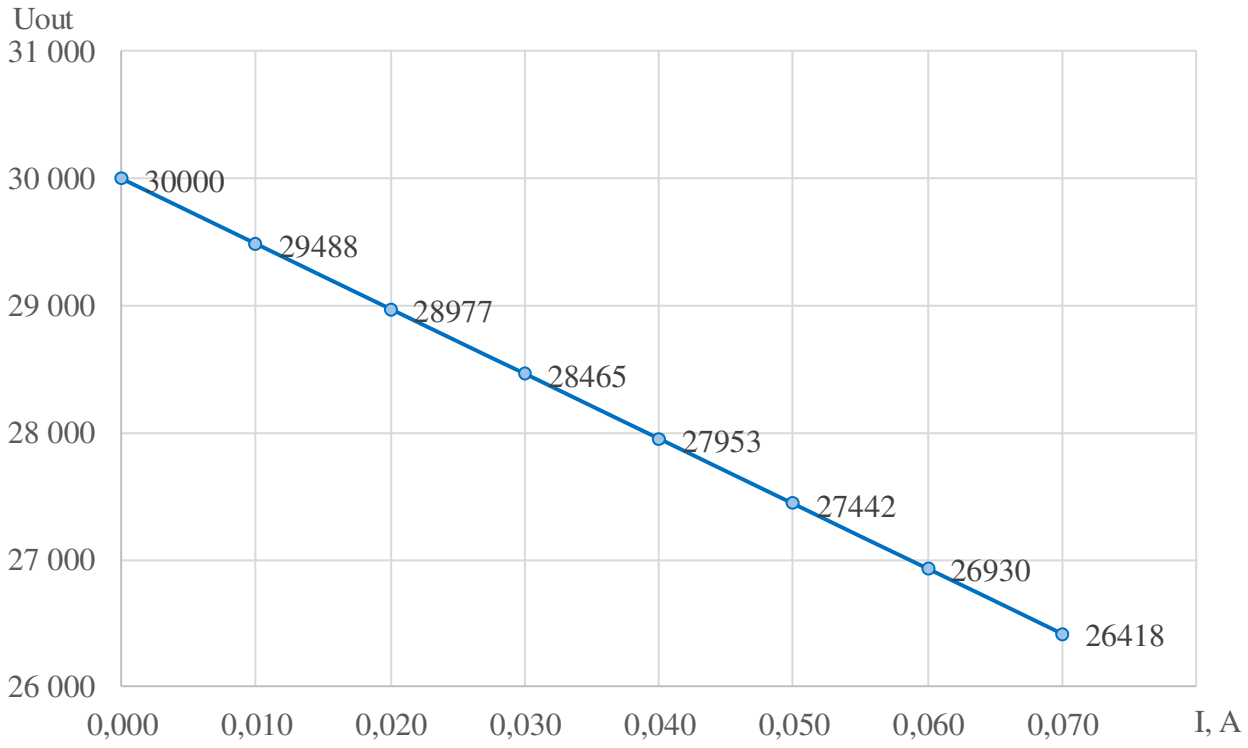

Fig. 7. External multiplier characteristic: $U_{\text {out }}=f(I)$

Analysis of the obtained characteristics of the voltage multiplier shows that to get the optimal value of the output voltage it is meaningless to increase the capacity of the capacitors above $50 \ldots 60 \mathrm{nF}$; as the multiplier load decreases, the output voltage increases proportionally; the optimal frequency of the multiplier power supply is in the range of $40 \ldots 50 \mathrm{kHz}$. 


\section{Conclusions}

1. The use of effective plant spraying with ionized aerosol used in mobile agricultural technology is complicated by the issues of electrical safety. The proposed spraying system allows the highvoltage installation to work safely.

2. The designed high voltage source, receives power from the tractor's on-board system. To create the required voltage (from 15 to $28 \mathrm{kV}$ ), at which air ionization occurs, the total capacitance of the voltage multiplier capacitors should not exceed $60 \mathrm{nF}$, and the power supply frequency should not exceed $50 \mathrm{kHz}$.

3. In general, the developed high voltage source to the spray system has a small mass, high reliability of operation with minimal dimensions and cost.

\section{References}

[1] Турчин И.А. Электризация рабочих жидкостей (Electrification of working fluids). // Journal of Plant Protection. - №9. - 1987. pp. 29-36. (In Russian).

[2] Nasr G.G., Yule A.J., Bendig L. Industrial Sprays and Atomization: Design, Analysis and Applications. Springer-Verlag London, 2002. 501 p.

[3] Антонов С.Н. Анализ существующих методов защиты растений (Analysis of existing methods of plant protection). / Methods and technical means to improve the efficiency of electrical equipment in industry and agriculture: a collection of scientific papers on the materials of the 82nd Scientific and Practical Conference of the Electric Power Department of Stavropol State University (Stavropol, 12.09.05.12.2016.). - Stavropol: AGRUS, 2016. - pp. 296-298. (In Russian).

[4] Antonov S.N., Gabriyelyan S.Z., Mastepanenko M.A., Zorina E.B., Nozdrovicky L The device of magnetic processing of water for boiler greenhouse. Research in agricultural engineering. Vol. 62, 2016, Special Issue: pp. 27-33.

[5] Архипов В. А. Аэрозольные системы и их влияние на жизнедеятельность (Aerosol systems and their influence on vital functions) / V.A. Arkhipov, U. M. Sheremetyeva. - Tomsk: TPU Publishing House, 2007. 136 p. (In Russian).

[6] Matthews G.A. Pesticide Application Methods. 3rd ed. - Wiley-Blackwell Science Ltd., 2000. $448 \mathrm{p}$.

[7] Antonov S., Nikitenko G., Adoshev A., Dorozhko S., Devederkin I. Method of effective spraying plants with drop charge of fertilizer solution by ionized air. Engineering for rural development, Jelgava, Latvia, 2018, pp. 519-523.

[8] Avdeeva, V.N., S.N. Antonov, A.G. Molchanov and I.V. Devederkin, 2017. Disinfecting of winter wheatgrain withelectrophysical factors. Engineering for rural development, Jelgava Latvia, pp. 323-327. 